\title{
Developmental stages and floral ontogenesis of foxtail millet Setaria italica (L) P Beauv
}

\author{
MO Blaise ${ }^{1}, \mathrm{P}_{\text {Girardin }}{ }^{1}$, B Millet $^{2}$ \\ 1 INRA, Laboratoire d'Agronomie, BP 507, F 68021 Colmar: \\ 2 Faculté des Sciences, Laboratoire de Botanique, Place Leclerc, F 25030 Besançon Cedex, France
}

(Received 1 July 1991; accepted 9 December 1991)

\begin{abstract}
Summary - A study of the morphological development of the shoot apex the floral ontogenesis of 2 varieties of foxtail millet was made by dissection of the shoot apex of the main stem at different stages of development. Photomicrographs of the principal stages show that the beginning of inflorescence differentiation (stage B) occurs at a thermal time of 705 degree-days (basis $6^{\circ} \mathrm{C}$ ) when the plants have $60 \%$ visible leaves. During floral ontogenesis panicle differentiation proceeds acropetally, but as there are more ramifications at the bottom of the inflorescence, the first spikelets to differentiate are located at the top. Within spikelets, floral parts differentiate in the following order: glumes, lemma, stamens, palea and pistil. Differentiation is very heterogeneous on the panicle and several developmental stages are present in the same secondary cluster. Anthesis starts at the top of the panicle where the spikelets are first differentiated. The heat sum required to reach this stage is 1004 degree-days and 1088 degree-days respectively for the 2 varieties and the thermal time for the total cycle of development is less than 1700 degree-days. This information is invaluable, when stress occurs, in determining which of the yield components is affected.
\end{abstract}

\section{Setaria italica / floral ontogenesis / developmental stages / differentiation}

Résumé - Stades de développement et ontogenèse florale chez le millet Setaria italica (L) P Beauv. Une étude du développement du bourgeon apical et de l'ontogenèse florale a été entreprise sur 2 variétés de millet des oiseaux par dissection de l'apex de la tige principale à différents stades du développement. Les photographies des principaux stades de l'apex montrent que le début de la différenciation de l'inflorescence (stade B) est atteint pour une somme de température de $705^{\circ} \mathrm{C}$.j (base $6{ }^{\circ} \mathrm{C}$ ). Les plantes ont alors $60 \%$ de feuilles visibles. Durant l'ontogenèse florale, la différenciation de la panicule est acropète, mais le degré de ramification étant plus élevé à la base, c'est au sommet que les premiers épillets se différencient. Pour un épillet, les pièces florales se différencient dans l'ordre suivant: glumes, lemmas (glumelles externes), étamines, paléas (glumelles internes) et pistil. Le long de la panicule, la différenciation est très hétérogène et l'on trouve plusieurs stades de développement dans une même grappe secondaire. La somme de températures nécessaire pour atteindre ce stade est de 1004 et $1088^{\circ} \mathrm{C}$.j respectivement pour les 2 variétés étudiées et de moins de $1700^{\circ} \mathrm{C}$.j pour la totalité du cycle. La connaissance de ces informations nous permet de savoir quelles composantes du rendement seront affectées en cas de stress intervenant pendant l'ontogénèse.

Setaria italica / ontogénèse florale / stade de développement / différenciation 


\section{INTRODUCTION}

Morphological development and growth stages of cereals are correlated with physiological and environmental characteristics and thus with characteristics of yield components. The knowledge of these stages is necessary to elucidate yield determining processes because yield components are determined at precise or given stages of development. Therefore an understanding of cereal plant development may giving insight into some aspects of crop production and may help to explain and predict the effects of stress on yield occurring at certain times during the life cycle. Because of these relationships, a characterization of growth and developmental stages of plants in morphological terms through the use of developmental scales is clearly desirable. Such scales have been established for the major cereal crops (Feekes scale, reviewed by Large, 1954; and Zadoks et $a /, 1974)$ and recommendations of the timing of many agricultural practices can be made for specific growth stages rather than for calendar days (Torigoe and Kurihara, 1981). These scales could also be used to standardize data obtained from different sources. To establish such scales, the general phases of development and growth must be identified. The main stages should be easy to use in the field.

The developmental morphology of the cereal shoot apex has been the subject of many studies. Tassel and ear development of maize have been described by Bonnett (1948) and reviewed in Bonnett (1966) and Gay and Menetrier (1978). Bonnett (1935, 1936, 1937, 1966) has also studied the inflorescence development of other cereal crops. Sharman (1947) has described the development morphology of the shoot apex in the Gramineae. Anderson (1952) has presented methods for determining stages of development in barley and oats. Kirby (1974) has described ear development in spring wheat and Kirby and Appleyard (1984) in wheat and barley. Sundberg and Orr (1986, 1990) and Sundberg (1987) have examined inflorescence development in teosinte and give a description of the ontogeny of the inflorescence.

No study of panicle development of foxtail millet Setaria italica has been published in the literature. This cereal is widely cultivated in China, Japan and India for human consump- tion and we expect to reintroduce this cereal into Western Europe.

The aim of this paper is to give a detailed description of panicle development in foxtail millet and to link the developmental stages to the main developmental and growth phases expressed in terms of heat sum units.

In order to describe floral ontogenesis, developmental stages of the shoot apex are recorded according to the scale shown in table 1. The decimal code developed by Zadocks et al (1974), which is numbered in ontogenetic order from seedling emergence until grain maturity for several cereals, only refers to the principal growth stages which are easily recognizable under field conditions with very few details on ontogenesis. We have chosen as reference the scale used by Gay and Menetrier (1978) illustrating tassel morphogenesis of maize. With this kind of information it is possible to determine whether a specific yield component is affected, when stress occurs, the setup of each yield component being well known.

\section{MATERIALS AND METHODS}

\section{Plant material and culture conditions}

Two varieties of foxtail millet (Setaria italica (L) P Beauv were used for this study. The Chinese cultivar "Change with Ageing" called "Change" was a medium tillering type, and "Burganjou" of French origin was a monotillering one.

The field experiment was carried out in 1988 at the Huben site (INRA Colmar, France) on a loamy deep soil, in a split-plot design with 4 replicates. Fertilizers were applied before planting at rates of $145-145-145 \mathrm{~kg} \mathrm{ha}^{-1}$ of N-P-K. The density of sowing was 60 plants $\mathrm{m}^{-2}$. The plants were thereafter thinned to 30 plants $\mathrm{m}^{-2}(0.30 \mathrm{~m}$ inter-row and $0.12 \mathrm{~m}$ inter-plant). The other cultural techniques were typical for this area: sowing date on May 2nd, weeding on May 25th and harvest on October 12th. Heat sum was calculated from a $6^{\circ} \mathrm{C}$ basis (according to Bloc and Gouet (1977) in maize) from the sowing date.

\section{Development characteristics}

Measurements of plant height (from plant collar to the highest leaf tip) and leaf number (visible leaves and expanded leaves) were recorded in 15 plants which were randomly selected from each replicate after sowing. Temperature units for different 
Table I. Notation scale established to record principal phases of development in foxtail millet.

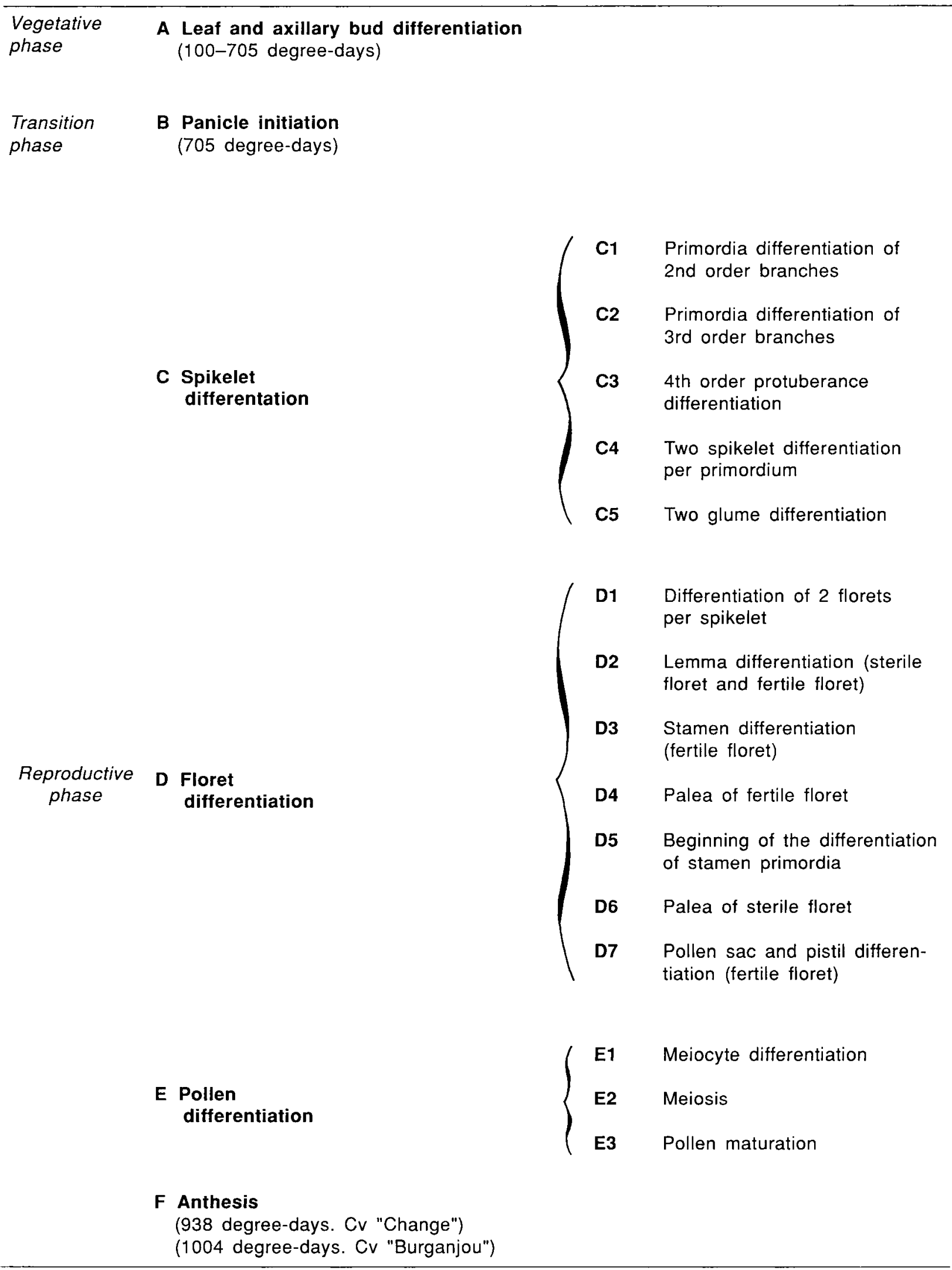


developmental stages (germination, heading, anthesis and physiological maturity) were calculated from the date of sowing to the date when $50 \%$ of the plants per plot reached this stage.

Observations were made twice a week on both varieties (main stem only) in order to ensure identification of all developmental stages of the panicle. A minimum of 5 plants, selected randomly from each replicate, was examined to obtain a reliable estimate. Precise identification of the morphogenesis of the shoot apex was made by dissection and examination under scanning electron microscope (SEM). The stage of apex development was classified on the basis of the type of primordia most recently differentiated (Anderson, 1952; Bonnett, 1966).

\section{Sample preparation procedure for SEM}

After dissection, the samples were fixed for $24 \mathrm{~h}$ in a cold fixative Navashine solution (solution $A$ : $5 \mathrm{~g}$ chromic acid dissolved in $50 \mathrm{ml}$ acid acetic and $320 \mathrm{ml}$ of distilled water was mixed V/V with solution B: $200 \mathrm{ml}$ of formaldehyde $40 \%$ and $175 \mathrm{ml}$ of distilled water). The samples were then dehydrated in a graded ethanol series $170 \%, 95 \%$ and $100 \%$ ).

For examination under the SEM, the samples were carefully transferred to special capsules and soaked in 3 acetone baths for a gradual replace-

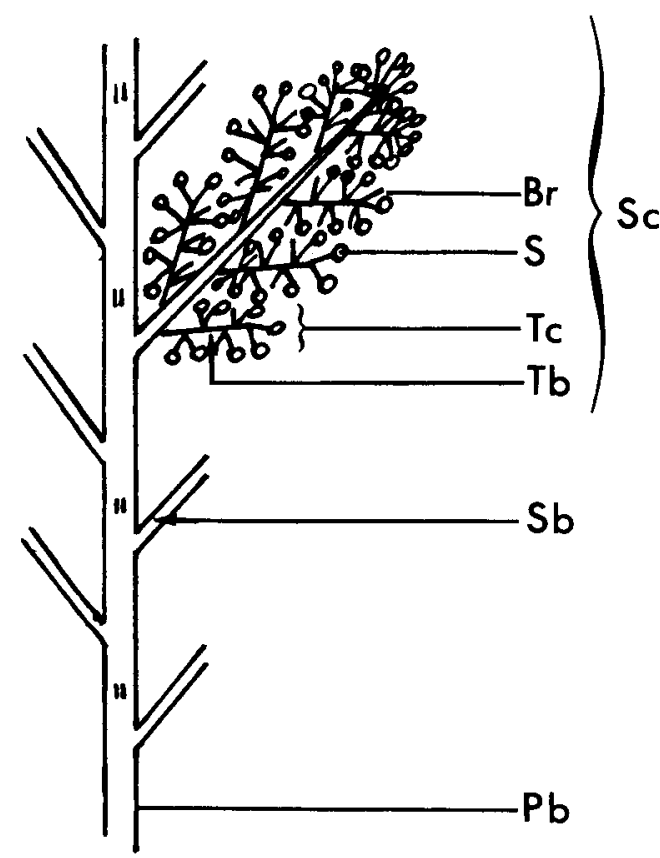

ment of absolute ethanol by acetone to ensure good dehydration. Then the capsules were placed in the basket contained in the pressure bomb of the critical point drying apparatus. Acetone was gradually exchanged with liquid $\mathrm{CO}_{2}$ during a series of 3 flushes. With the bomb fully pressurized, the chamber was heated to $40^{\circ} \mathrm{C}$ for $20 \mathrm{~min}$ for atomization of liquid $\mathrm{CO}_{2}$. The critical point-dried samples were immediately prepared for metal coating: they were mounted on aluminium discs and a thin gold film was deposited on them. The coated samples were then ready for examination under SEM.

\section{RESULTS}

\section{Organization of the panicle}

In order to analyze the morphological development of the shoot apex, a description of the mature panicle and a spikelet diagram are given below (fig 1a, 1b).

The foxtail millet inflorescence is a terminal nodding panicle with a length of $10-40 \mathrm{~cm}$ and a diameter of $2-4 \mathrm{~cm}$. This panicle can be compared to a primary cluster made up of several secondary clusters (Sc), small rounded spikes, which are visible in both

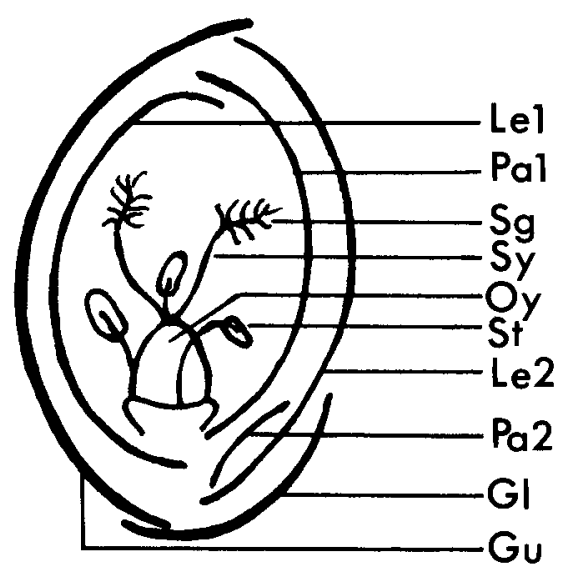

Fig 1a. Organization of a mature panicle of foxtail millet. Basal region $(1 / 3<)$ of the panicle $(\times 1)$. Primary branch $(\mathrm{Pb})$, secondary branch $(\mathrm{Sb})$, tertiary branch $(\mathrm{Tb})$, secondary cluster $(\mathrm{Sc})$, tertiary cluster (Tc), spikelet $(\mathrm{S})$, bristle (Br). b. Spikelet diagram (approximately $\times 25$ ). Lower glume $(\mathrm{Gl})$, upper glume $(\mathrm{Gu})$, lemma of floret 1 (Le1), lemma of floret 2 (Le2), palea of floret 1 (Pa1), palea of floret 2 (Pa2), stamen (St), ovary (Oy), stigma (Sg), style (Sy). 
varieties. The second order clusters are made up of third-order clusters (TC) and are arranged in a helicoidal disposition on the panicle. The third order clusters consist of a few spikelets (up to 10). The secondary clusters are generally sparse at the bottom of the inflorescence and densely aggregated at the top, with up to 40 spikelets (S) for $\mathrm{Cv}$ "Burganjou" and up to 100 spikelets for $\mathrm{CV}$ "Change". The spikelets are glabrous, elliptic to obovate and consist of 2 florets, the lower one sterile, the upper one fertile with 3 stamens and a pistil. A spikelet is about $2 \mathrm{~mm}$ long with 1 or no bristle $(\mathrm{Br})$ at the base. The length and density of these bristles on the panicle depend on the varieties: $1 \mathrm{~cm}$ for "Change"; they are shorter $(0.5 \mathrm{~cm})$ and less numerous in "Burganjou".

\section{Developmental stages}

The developmental stages and floral ontogenesis were investigated for both $\mathrm{Cv}$ "Change" and "Burganjou". The observations on stem apex and inflorescence morphology and chronology of the initiation of spikelet floral parts are identical for the 2 varieties. We have therefore chosen the most relevant photographs to illustrate the results.

\section{Seedling emergence}

Under controlled conditions (imbibition on filter paper at a temperature of $25^{\circ} \mathrm{C}$ ) the cary-

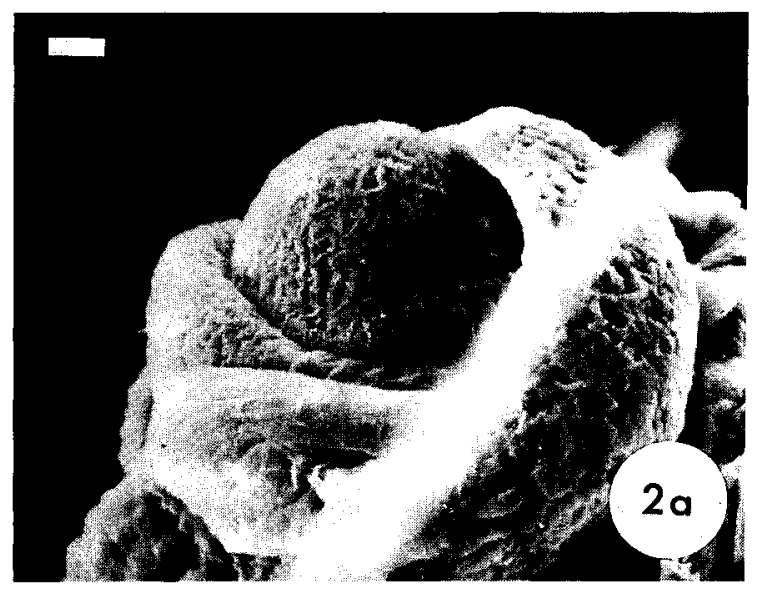

opses germinate after about $36 \mathrm{~h}$. Seeds sown in the field on May 2nd 1988 emerged 9 days later. For both varieties, $50 \%$ of the plants reached this stage by May 11th (100 degree-days).

The coefficient of variation (CV) for this stage was $16 \%$ for "Burganjou" and 20\% for "Change".

\section{Characteristic stages of apical meristem development}

\section{Vegetative phase}

During the vegetative period of foxtail millet the shoot apex initiates leaf primordia (Lp) in a distichous pattern. Figures $2 \mathrm{a}$ and $2 \mathrm{~b}$ show an apical meristem in the vegetative stage. The apical dome (D) is about $0.05 \mathrm{~mm}$ long and is rounded. Each leaf starts as an initial ridge, the leaf initium ( $\mathrm{Li}$ ), around the developing shoot apex just below its hemispherical growing point.

\section{Transition phase}

During the transition to flowering the apex stops producing leaves. The first indication of differentiation into a young inflorescence is an elongation and enlargement of the vegetative apex (fig 3a, 3b). This is an important stage in cereal development (stage B). Because of the influence of management and environment upon yield components, the knowledge of this principal stage is a prime necessity. Stage $B$

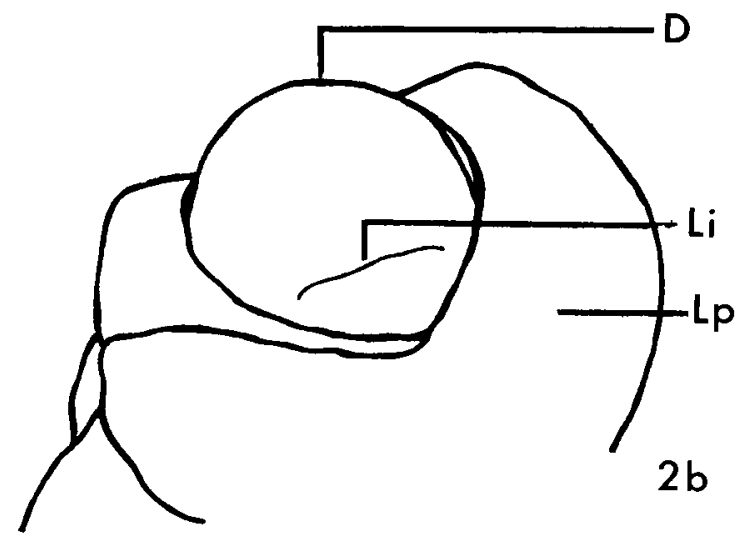

Fig 2. Shoot apex of a millet plant with 6 visible leaves prior to dissection. CV "Change" (25-day-old plant). Stage A. Apical dome (D), leaf initial (Li), leaf primordium (LP). a. SEM photomicrograph. Scale bar $=10 \mu \mathrm{m}$. b. Drawing of the same apex. 

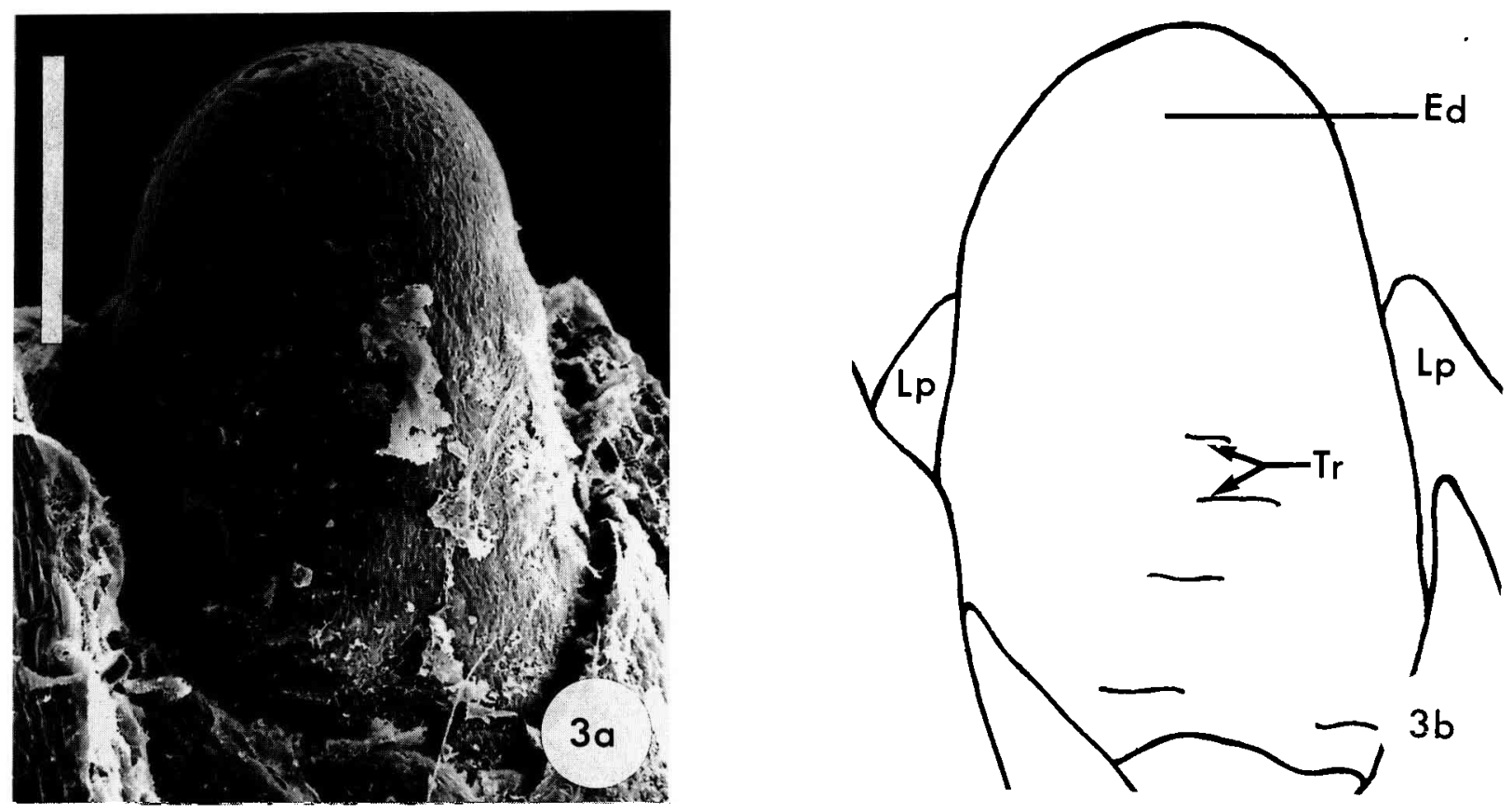

Fig 3. Elongation of the shoot apex and appearance of the first transverse ridges (64-day-old plant, CV "Change"). Stage B. Elongated dome (Ed), transverse ridges (Tr), leaf primordium (Lp). a. SEM photomicrograph. Scale bar $=100 \mu \mathrm{m}$. b. Drawing of the same apex.

marks the beginning of the panicle initiation and if a stress occurs after this stage panicle development could be affected. For both varieties the floral initiation stage was reached by July 5th (64-day-old plants). Thermal duration (basis $6^{\circ} \mathrm{C}$ ) was 705 degree-days. Number of visible leaves was $13.2(60 \%$ of visible leaves) for "Change" and 11.8 (60\% of visible leaves) for "Burganjou". Average plant height was $53 \mathrm{~cm}$ for "Change" and $63 \mathrm{~cm}$ for "Burganjou". At this stage the vegetative apex was $0.25 \mathrm{~mm}$ long. At the bottom of figure 3 , several leaf primordia are visible. On the elongated dome $(E d)$ the first transverse ridges (Tr) appear. Floral differentiation begins at the base and proceeds acropetally.

No variability was observed for the date of appearance of this stage which occurred, for both varieties, on the same day for all sampled plants.

\section{Reproductive phase}

\section{Spikelet differentiation}

The differentiation of the future inflorescence proceeds with the emergence of protuberances, the 2nd order branch primordia (B2) (stage $\mathrm{C} 1$ ). These protuberances arise in an acropetal sequence according to a helical phyllotaxy (fig 4c). An apex at this stage is shown in figure $4 \mathrm{a}$ and $4 \mathrm{~b}$. Figure $4 \mathrm{c}$ illustrates an apex in top view. We can distinguish 8 rows of secondary branch primordia. The mature panicle is generally composed of 8 secondary cluster rows in these 2 varieties. Four out of the 5 observed plants of both variety had reached this stage by July 7th (66-day-old plants, ie 725 degree-days).

Each 2nd-order meristematic dome divides (fig 5a, 5b) and gives rise to several 3 rd-order branch primordia (B3) (stage C2). Within the future secondary cluster, the 3rdorder branch primordia arise in an acropetal succession and are produced in 2 opposite ranks (fig $5 a, 5 b$ ). Therefore branching of the secondary clusters appears to be distichous and alternate. Branching is more prolific at the bottom of the young inflorescence and this part of the panicle consists of more tertiary spikelet clusters than the panicle tip.

Subsequently, the initiation of 4th-order protuberances (P4) takes place along the 3rdorder axis perpendicular to the 2nd-order axis (fig 6a1, 6b1). The appearance of the 4thorder protuberances (stage C3) is identical to that observed for the 3rd-order branch primordia (distichous and alternate). The 4th-order protuberances that will produce spikelet primordia are initiated in a greater number at 

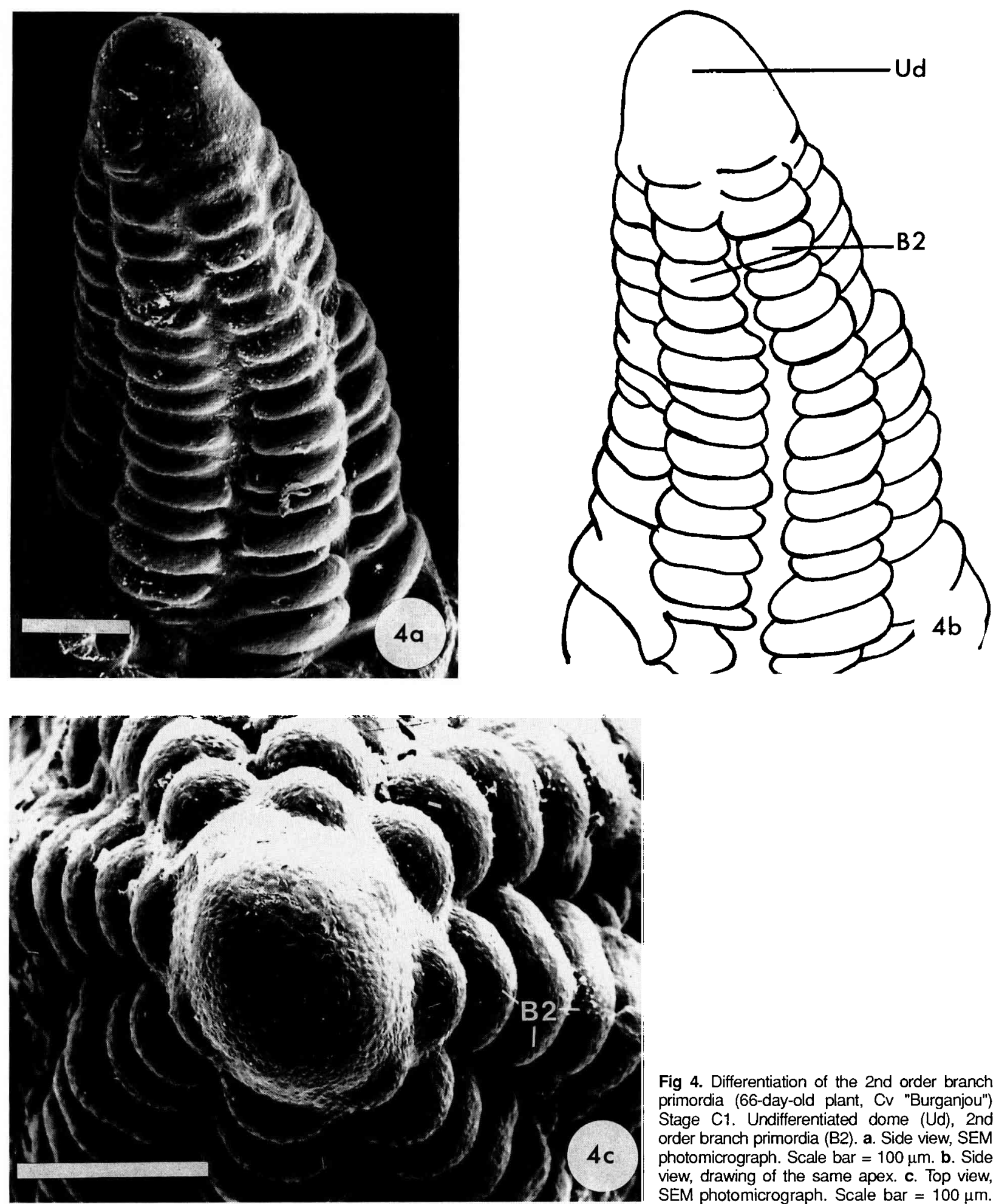

Fig 4. Differentiation of the 2nd order branch primordia (66-day-old plant, Cv "Burganjou") Stage $\mathrm{Cl}_{1}$. Undifferentiated dome (Ud), 2nd order branch primordia (B2). a. Side view, SEM photomicrograph. Scale bar $=100 \mu \mathrm{m}$. b. Side view, drawing of the same apex. c. Top view, $\mathrm{SEM}$ photomicrograph. Scale bar $=100 \mu \mathrm{m}$.

the bottom of the inflorescence (fig 6a1, 6b1) than at the tip. Therefore, the tertiary clusters of the lower part of the panicle contain more spikelets.

Spikelet development (stage C4) starts at the top of the young panicle even through 3rd- order meristems continue to divide at the bottom and produce several 4th-order protuberances (fig 6a, 6b). At this stage, differentiation is therefore more advanced at the tip even though during the first developmental stages there was an acropetal differentiation. At the 

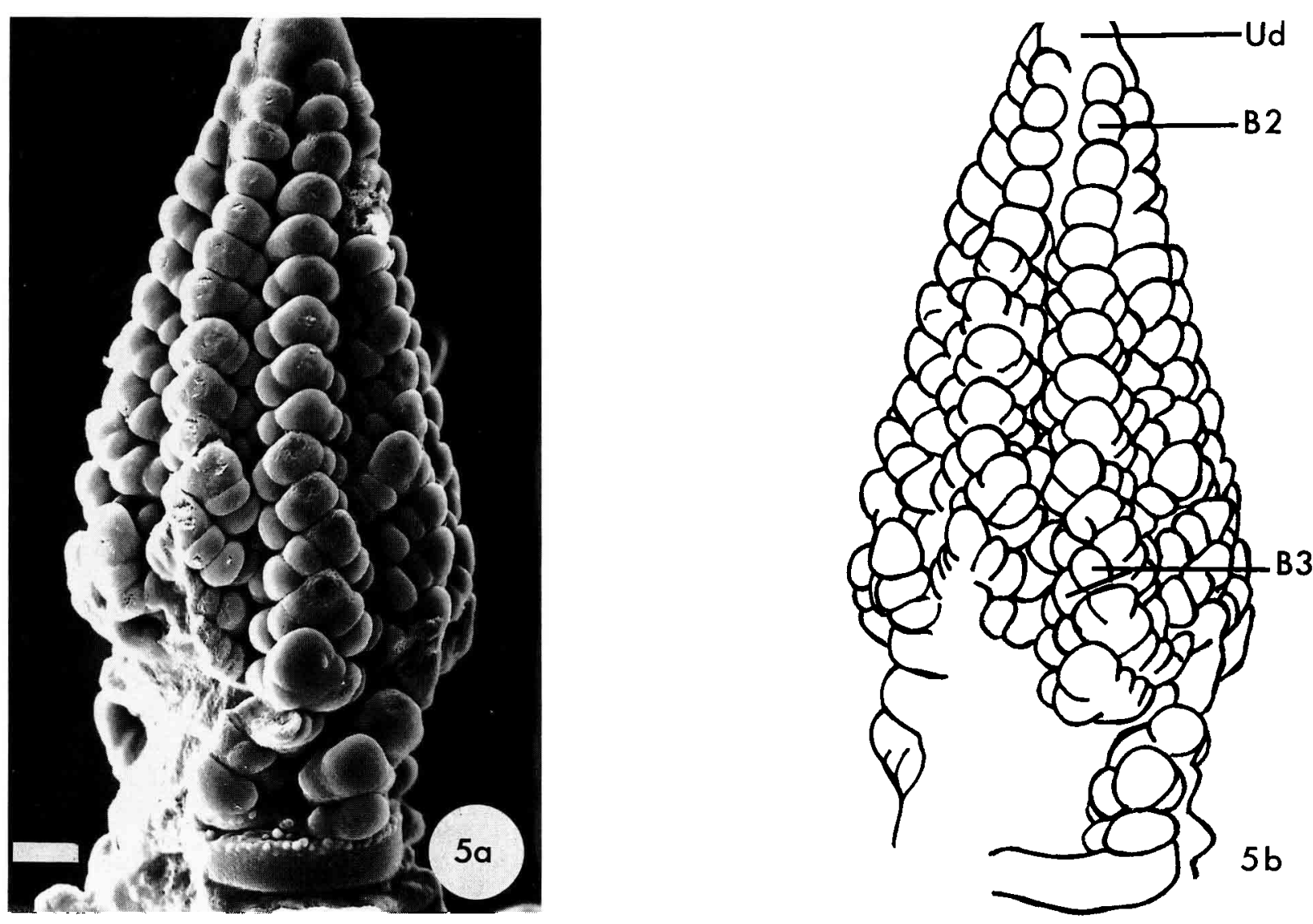

Fig 5. Differentiation of the 3rd order branch primordia (68-day-old plant, CV "Change"). Stage C2. Labelling as in figure 4; 3rd order branch primordia (B3). a. SEM photomocrograph. Scale bar $=100 \mu \mathrm{m}$. b. Drawing of the same apex.

beginning of spikelet development, the 4thorder protuberances divide into 2 more or less unequal parts, the spikelet primordia (Sp) (fig 6a2, 6b2) which later elongate and differentiate into spikelets. Six out of the 8 observed plants in "Burganjou" and 5 out of the 6 observed plants in "Change" had reached this stage by July 11th (70-day-old plants, ie 773 degree-days).

It seems that the bristles $(\mathrm{Br})$ originate from aborted spikelet primordia. Figure 11 represents the base of an inflorescence at a later developmental stage. Either 2 spikelets (S) or 1 spikelet and 1 bristle develop from the 2 spikelet primordia. The distinction between them is easy because the bristle tips are truncated at this stage (figs 8-11). It should be noted in figure 11 that several stages of spikelet development are shown on the same secondary cluster and thus the differentiation is very heterogenous even within a cluster.

The empty glumes are the first parts of the spikelets to develop (stage C5) and arise as transverse ridges across the spikelet primordia (fig 7). The lower glume (Gl) appears first abaxially near the base of the spikelet primordium. The upper glume (Gu) arises subsequently, slightly above and opposite the lower one (fig 7).

\section{Floret differentiation}

After the 2 glumes initiate, floret differentiation takes place on the apical meristem (stage D). In each spikelet, 2 florets develop from the rounded meristem located above the glume primordia (stage D1). This meristem divides into 2 parts; the floral primordia (fig 8). The upper one gives rise to the fertile floret (F/1), and the lower one develops into the sterile floret (FI2).

At the same time, the aborted spikelet primordia continue to elongate and the first indication of their development into bristles is manifested by a constriction of their tip (figs 7 , 8).

The empty glumes increase in size and encircle the spikelet axis. The lower glume partly covers the external edges of the upper one. Over and opposite the upper glume insertion, a crescent-shaped primordium is initiated 

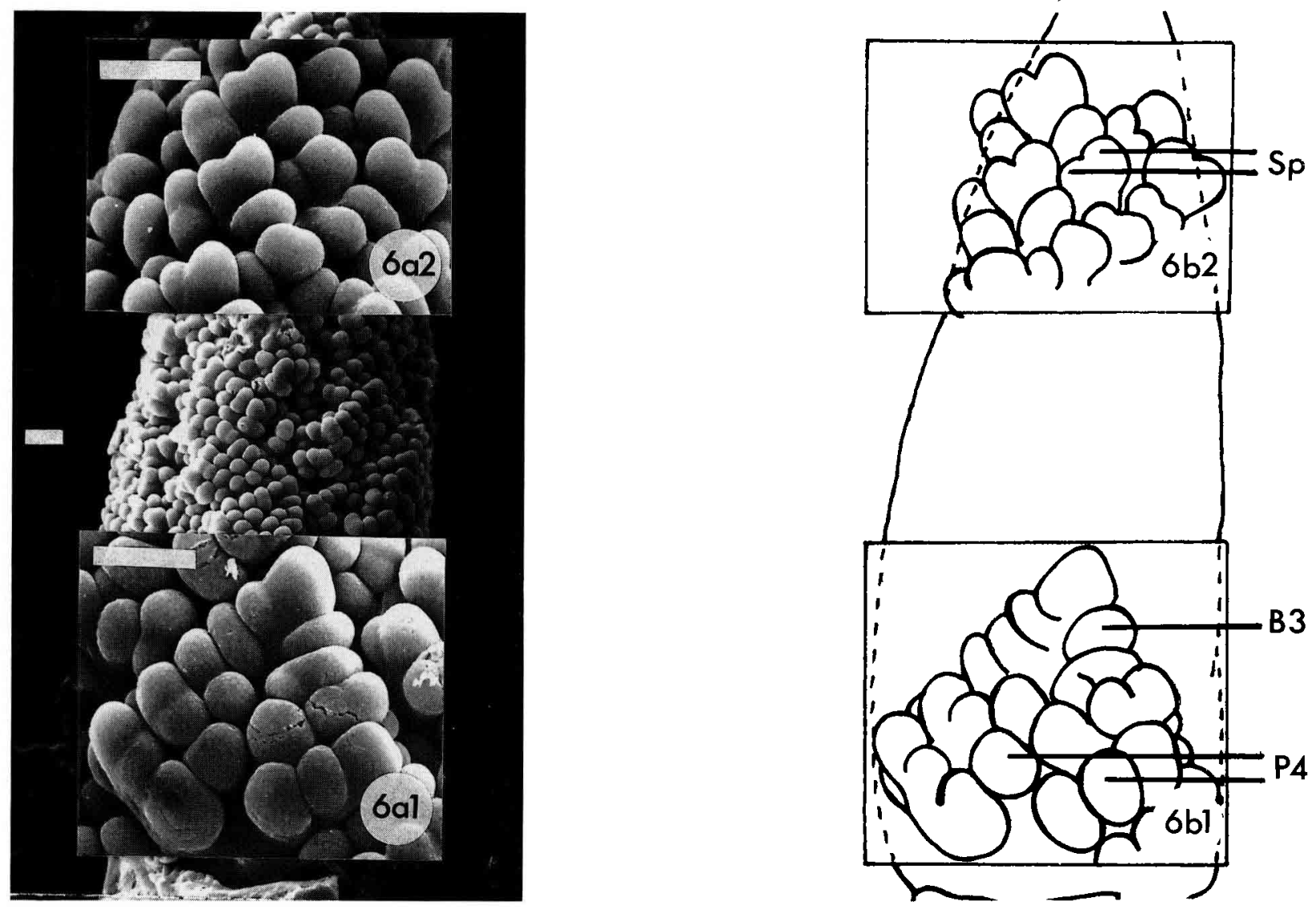

Fig 6. a1-b1: Initiation of the 4th order protuberances at the bottom of the inflorescence. a2-b2: differentiation of 2 spikelet primordia at the top of the inflorescence (70-day-old plant, Cv "Change"). Stages C3 and C4. Labelling as in figure 5; spikelet primordia (Sp), 4th order protuberances (P4). a. SEM photomicrograph. Scale bars $=100 \mu \mathrm{m}$. b. Drawing of the same apex.

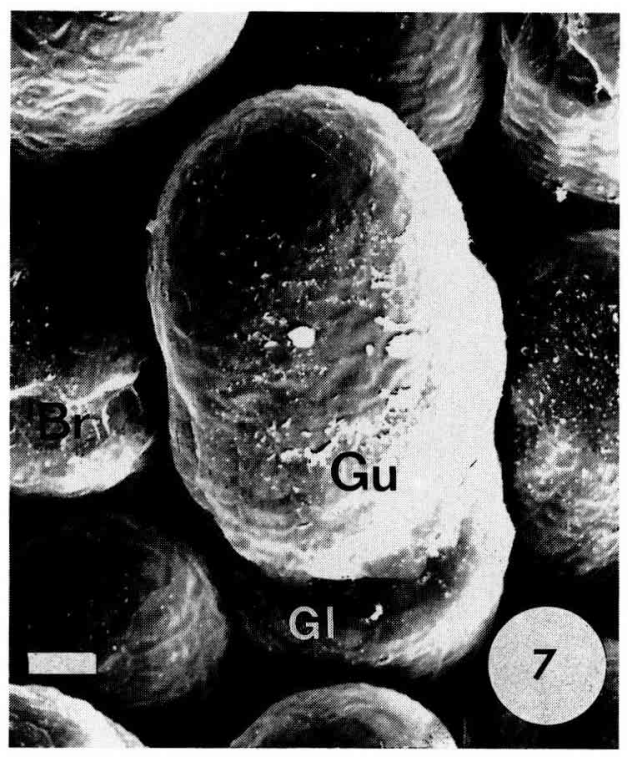

Fig 7. Differentiation of the 2 empty glumes, and differentiation of the bristles (70-day-old plant, Cv "Change"). Basal part of the inflorescence. Stage C5. Lower glume (Gl), upper glume $(\mathrm{Gu})$, bristle $(\mathrm{Br})$. Scale bar $=10 \mu \mathrm{m}$.

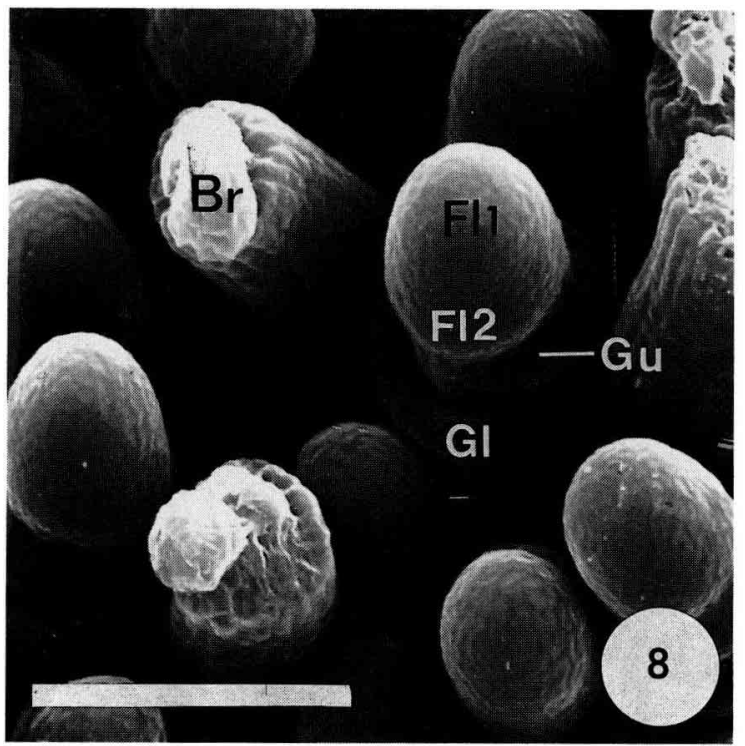

Fig 8. Differentiation of 2 floret meristems (70-day-old plant $\mathrm{CV}$ "Change"). Upper part of the inflorescence. Stage D1. Labelling as in figure 7; floret $1=$ fertile floret $(F \mid$ 1). Floret 2 = sterile, floret $(F \mid 2)$. Scale bar $=100 \mu \mathrm{m}$. 
(figs 9,10 ). It will form the lemma (Le2) of the sterile floret (stage D2). Its further development is the same as those of the empty glumes.

Following this stage of development, a rounded meristematic dome (Rm2) arises over the middle part of the lemma of the sterile floret primordia. At the same time, the lemma primordium of the fertile floret (Le1) appears on the other side of the spikelet axis (fig 10).

Soon after, the stamens of the fertile floret (St1) are initiated as 3 protuberances from the meristem located above (fig 12) (stage D3). The 2 dorsal stamens seem to appear first. They are diametrically opposite one another. The 3rd stamen arises perpendicular to the axis defined by the other 2 stamens (fig $13 a$, $13 \mathrm{~b}, 14 \mathrm{a}, 14 \mathrm{~b})$. The initium between the 2 dorsal stamens will later differentiate into the pistil. Just after this developmental stage, Sundberg and Orr (1986) have observed the lodicule initiation located "slightly below and in alternation with stamen primordia" (in teosinte). We have never observed the presence of the lodicule primordia. Perhaps this

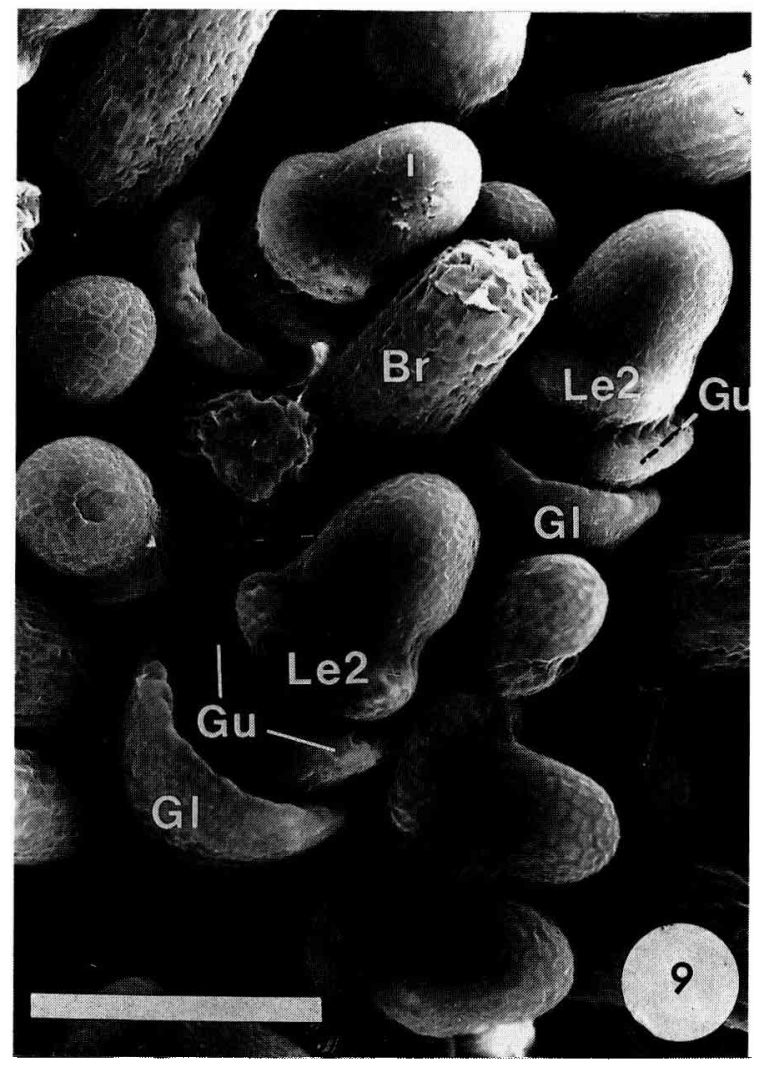

Fig 9. Differentiation of the sterile floret lemma (72-dayold plant, $\mathrm{CV}_{V}$ "Change"). Basal part of the inflorescence. Stage D2. Labelling as in figure 7; lemma of floret 2 (Le 2). Scale bar $=100 \mu \mathrm{m}$. stage occurs subsequently in the development of the inflorescence of millet and for reasons mentioned later it could not be described.

As the 3 stamen primordia are formed, a crecent-shaped primordium can be distin-

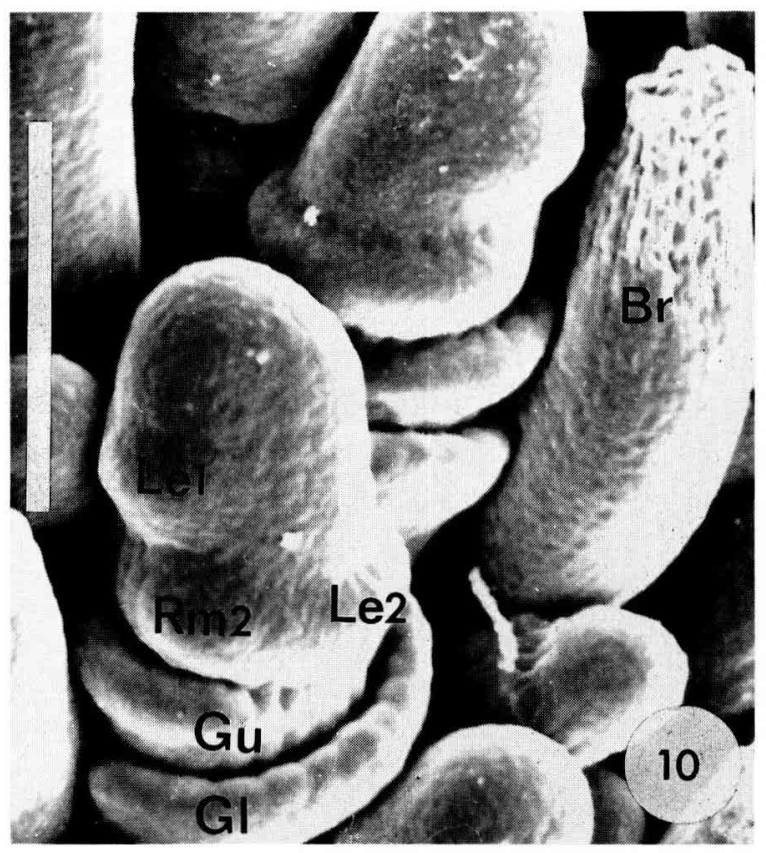

Fig 10. Differentiation of the fertile floret lemma and initiation of the rounded meristem of the sterile floret (72-dayold-plant, Cv "Change"). Basal part of the inflorescence. Stage D2. Labelling as in figures 7-9; lemma of floret 1 (Le1), rounded meristem of floret $2(\mathrm{Rm} 2)$. Scale bar = $100 \mu \mathrm{m}$.

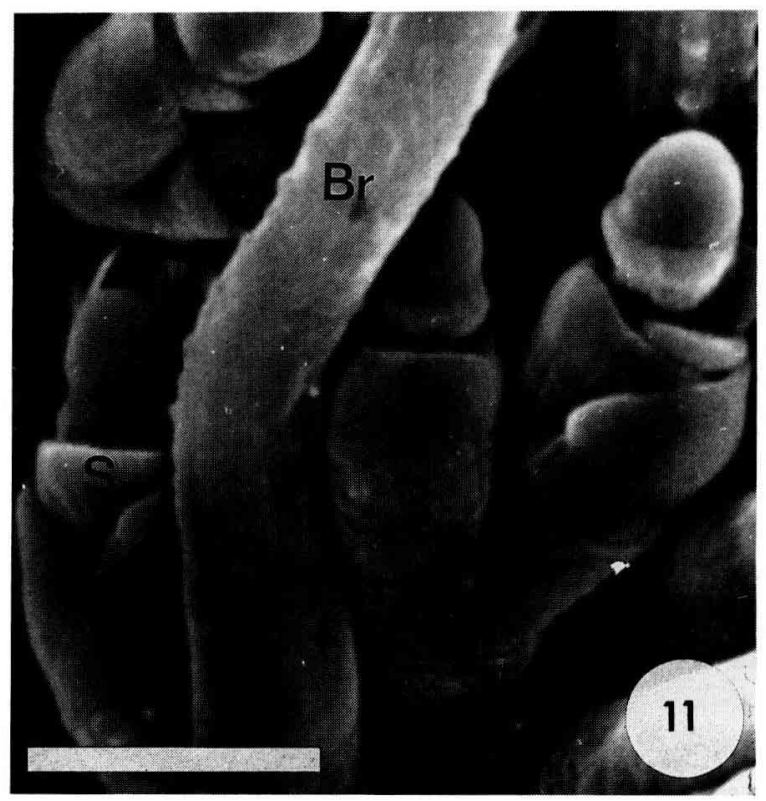

Fig 11. Basal part of the inflorescence showing the origin of the bristle. (74-day-old plant, $\mathrm{CV}_{V}$ "Change"). Spikelet (S), bristle $(\mathrm{Br})$. Scale bar $=100 \mu \mathrm{m}$. 
guished over the lemma of the fertile floret (fig 13a, 13b) and it seems to be initiated after the stamens. This is the palea primordium of the fertile floret (Pa1) (stage D4). The rounded

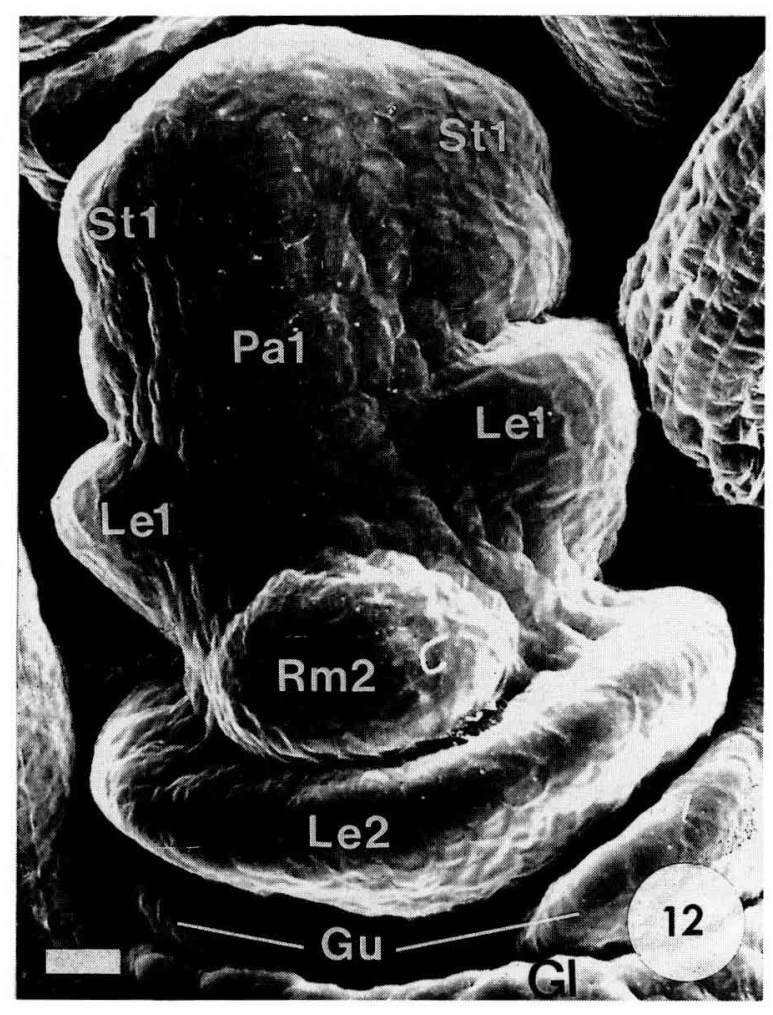

Fig 12. Differentiation of the fertile floret palea and appearance of the stamen primordia (72-day-old plant, $\mathrm{Cv}$ "Change"). Transition region of the inflorescence. Stage D3-D4. Labelling as in figures 7, 9, 10; stamen of floret 1 (St 1), palea of floret 1 (Pa1). Scale bar $=10 \mu \mathrm{m}$.

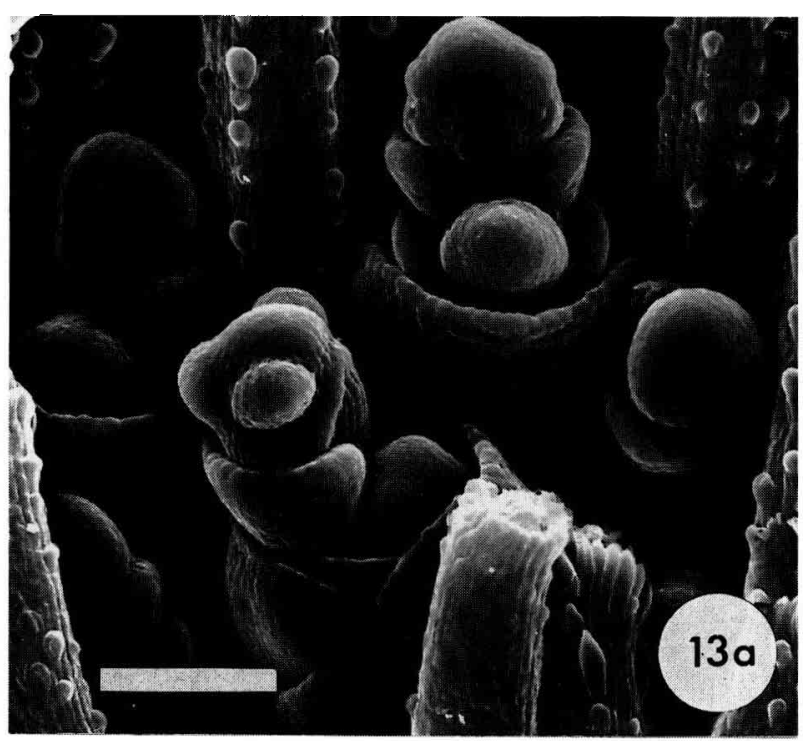

meristem of the sterile floret divides into 4 parts (fig $14 \mathrm{a}, 14 \mathrm{~b}$ ); 3 of them are the stamen primordia (St2) (stage D5) but their development is aborted and the last one will form the palea (Pa2) of the sterile floret (stage D6).

Anther primordia then begin to differentiate (stage D7) and the 4 pollen sacs (Ps) or locules can be identified in figure $15 \mathrm{a}$ and 15b. Pistil $(\mathrm{Pi})$ differentiation begins with the formation of a crescent-shaped ridge (R) which does not at first completely encircle the initial. It is more prominent on the side of the anterior stamen. The ovule primordium (O) arises on the opposite side between the ridge extremities. Then pistil development continues with the extension of the ridge enclosing the ovule initial (fig 15a, 15b).

Differentiation and development of the other pistil parts (styles and stigmas) could not be described because of growth of the lower glume which entirely encloses the other floral parts (fig 16). At the developmental stage described in figure $15 \mathrm{a}, 15 \mathrm{~b}$, the spikelet is very small $(0.25 \mathrm{~mm})$, the bristles are longer and they often completely cover the spikelets. Furthermore, the spikelet tissues break easily. Therefore the glumes were not removed and further development of the gynoecium was not investigated here.

It is difficult to record the exact time required for the entire differentiation of the spikelet because, as mentioned above, differentiation is not synchronous on the panicle. At first, it appears on the upper part of the

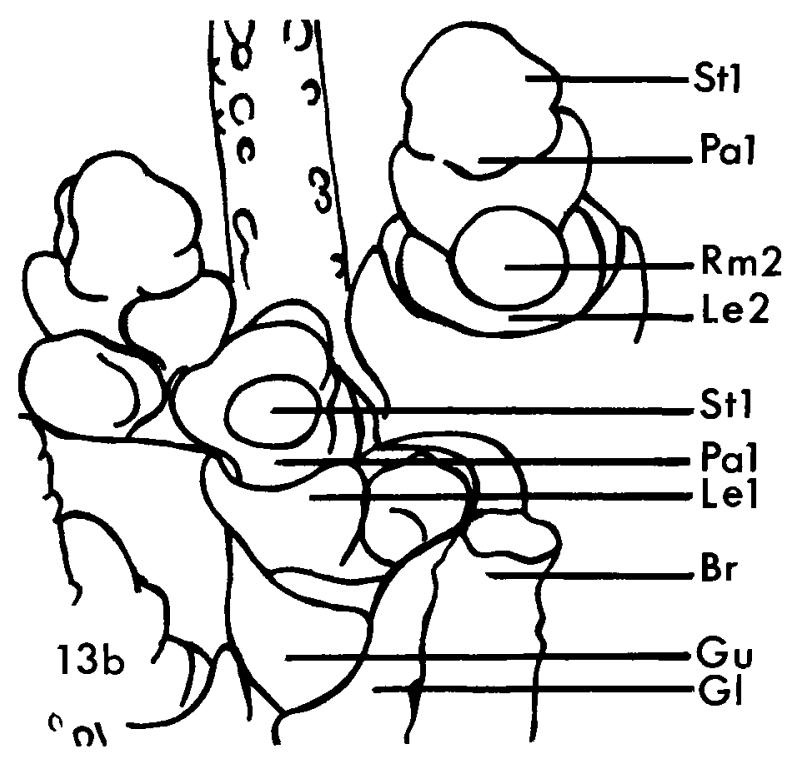

Fig 13. Palea and stamen differentiation of floret 1. Stage more advanced than in figure 12 (74-day-old plant, Cv "Change") Basal part of the inflorescence. Labelling as in figures 7, 9-12. a. SEM photomicrograph. Scale bar $=100 \mu \mathrm{m}$. b. Drawing of the same apex. 

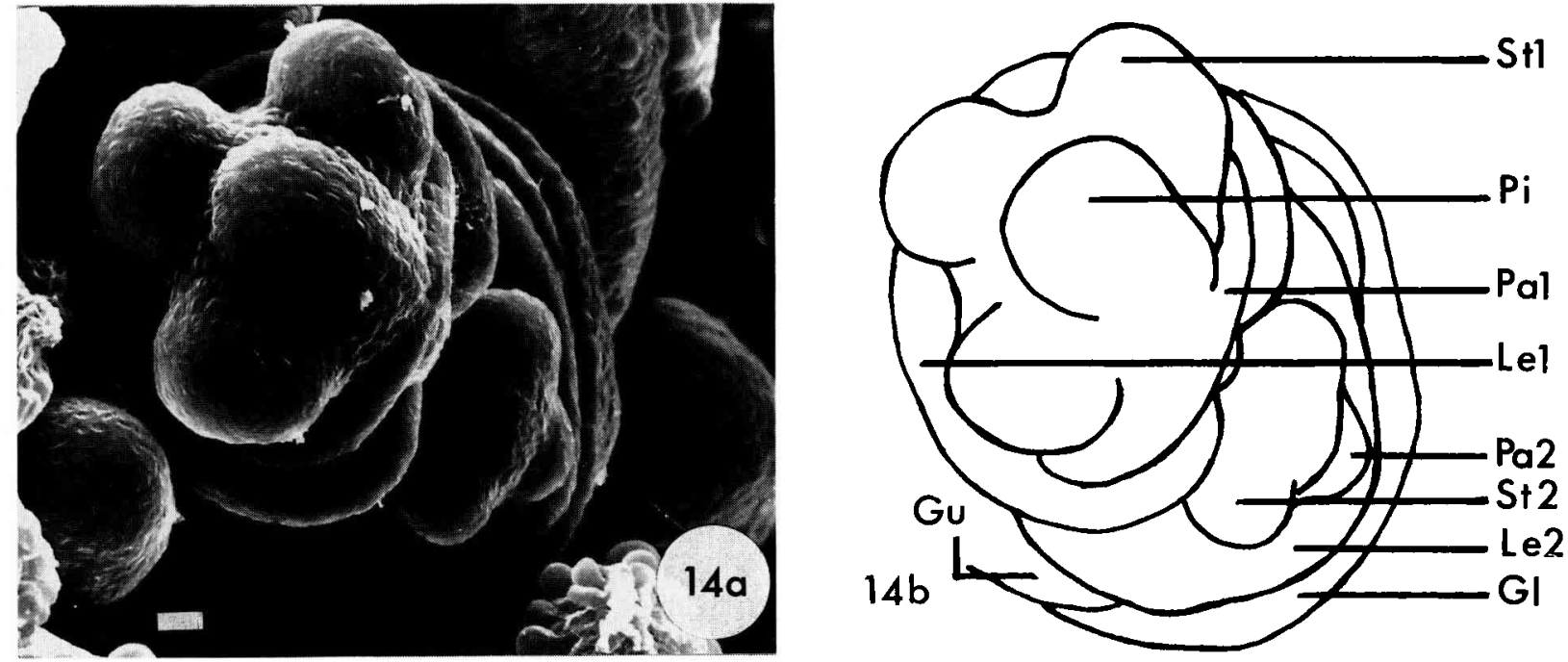

Fig 14. Top view of a spikelet at stage D5 and D6 (74-day-old plant, Cv "Change"). Transition part of the inflorescence. Labelling as in figures $7,9,12$; pistil ( $\mathrm{Pi}$ ), stamen of floret 2 (St2), palea of floret 2 (Pa2). a. SEM photomicrograph. Scale bar $=10 \mu \mathrm{m}$. b. Drawing of the same apex.
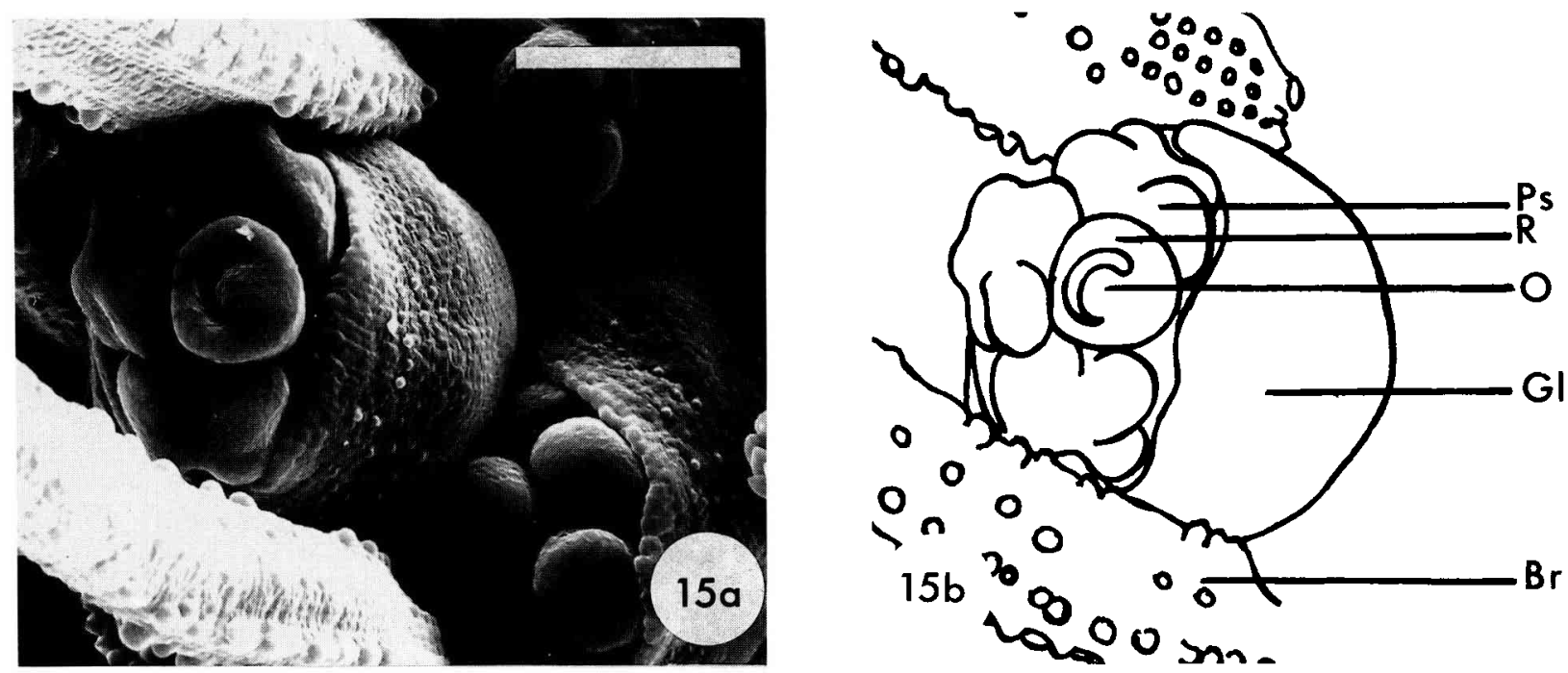

Fig 15. Pollen sac and pistil differentiation of the fertile floret. The lower glume covers the sterile floret (74-day-old plant, $C_{V}$ "Change"). Upper part of the inflorescence. Stage D7. Labelling as in figures 7, 9, 13; pollen sac (PS), ridge (R), ovule primordia (0). a. SEM photomicrograph. Scale bar $=100 \mu \mathrm{m}$. b. Drawing of the same apex.

inflorescence and proceeds downwards but within a same second order cluster, we find spikelets of several developmental stages. For both varieties that were studied, it took nearly 14 days (170 degree-days) for the differentiation of the whole spikelets, from stage $B$ to the stage presented in figure 16 . Heading occurred a few days later, on July 23th and 28th (938 and 1004 degree-days) for "Change" and "Burganjou" respectively. That represents fewer than 10 days (132 degreedays) after the end of spikelet differentiation.
The CV for appearance of heading was $2.2 \%$ for "Burganjou" and 1.8\% for "Change".

During the first stages of development, panicle initiation and differentiation proceed from the base upwards in acropetal succession. After stage C3, differentiation is more advanced at the tip and the first spikelets and bristles to differentiate appear at the tip of the young inflorescence.

Within the spikelet, the sequence of differentiation proceeds in the following order: 


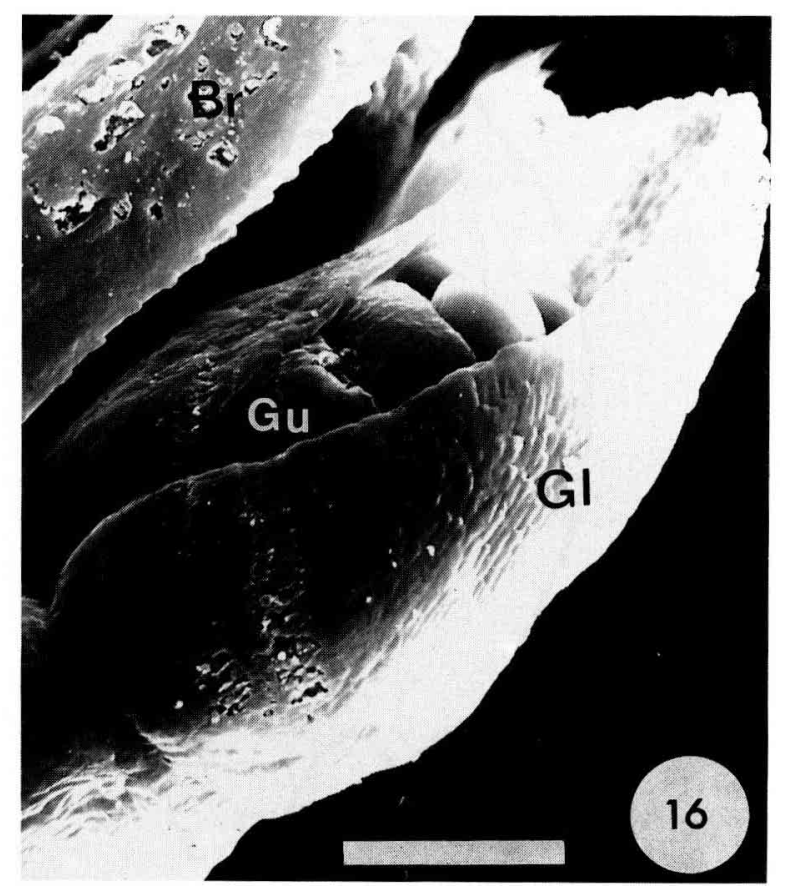

Fig 16. Maturing spikelet (76-day-old plant, Cv "Burganjou"). Labelling as in figure 7 . Scale bar $=100 \mu \mathrm{m}$.

lower glume, upper glume, lemma of sterile floret, lemma of fertile floret, stamens then palea of fertile floret, stamens then palea of sterile floret, pistil of fertile floret. Pollen differentiation was not investigated in this study.

\section{Anthesis}

Anthesis occurs, under normal conditions, a few days after head emergence; 5 days (67 degree-days) for "Change" and 7 days (84 degree-days) for "Burganjou". The CV for the appearance of anthesis was $4.5 \%$ for "Burganjou" and $2.9 \%$ for "Change".

Foxtail millet is an open flowering type and the flowers open gradually. In this flowering type, almost all carpels are pollinated by pollen from the same floret. Self-pollination is therefore a general rule. However, there is a low frequency of outcrossing (3\%) and hybrid plants can be seen in the next generation (Brabant et al, 1981). These authors observed several flowering types for the same panicleprotandry-slight protogyny-cleistogamy as influenced by temperature and moisture conditions.

Anthesis starts a little below the top of the panicle and proceeds downwards and upwards. It required about 2 weeks (188 degree- days for Burganjou" and 220 degree-days for "Change") for the whole flowering process because of the different precocity (a result of the non-homogeneous differentiation of the spikelets) of the flowers of the same secondary cluster. It should be noted that anthesis starts with the spikelets which are first differentiated, at the top of the inflorescence.

A mature floret in which anthesis is imminent is shown in figure $17 \mathrm{a}, 17 \mathrm{~b}$. The glumes, lemma and palea of the sterile floret and palea of the fertile floret have been removed. The lemma were partially dissected to reveal the fertile floral parts. At the base of the mature floret, we can see 2 lodicules (Lo). They swell at anthesis to induce the opening of glumes, lemma and palea. The anthers consist of 4 pollen sacs. Before anthesis, stamens have short filaments. These filaments elongate during anthesis which results in the emergence of the anthers (An). Behind the middle stamen, there is the swollen ovary (Ov), partly covered by the anthers and surmounted by the styles (Sy) and stigmas (Sg).

Figures $18 \mathrm{a}, 18 \mathrm{~b}$ show a spikelet at anthesis. The glumes are spread open and an anther as well as a stigma have been pushed out from the fertile floret. The stamen filament (Fi) which was short prior to the opening of the flower attains a length of $2.5 \mathrm{~mm}$ and holds the anther erect. At the bottom of the spikelet we can see 2 pilose bristles which are about $10 \mathrm{~mm}$ long in "Change", and $0.5 \mathrm{~mm}$ long in "Burganjou".

The inter-plant variability for the appearance of the main developmental stages is small. For both studied varieties, we noticed coefficients of variation $<5 \%$ for heading and anthesis.

\section{Developmental stages and growth}

The correspondence between the millet plant growth and the main developmental stages, expressed in terms of heat sum units, is shown in figure 19 for Cv "Burganjou". Plant height (expressed in $\mathrm{cm}$ ) represents the mean value of 15 plants. The low variation (coefficient of variation $<10 \%$ ) was not represented here.

Because of the influence of management and environment upon yield components, it is important to note the principal developmental stages of the crop. 

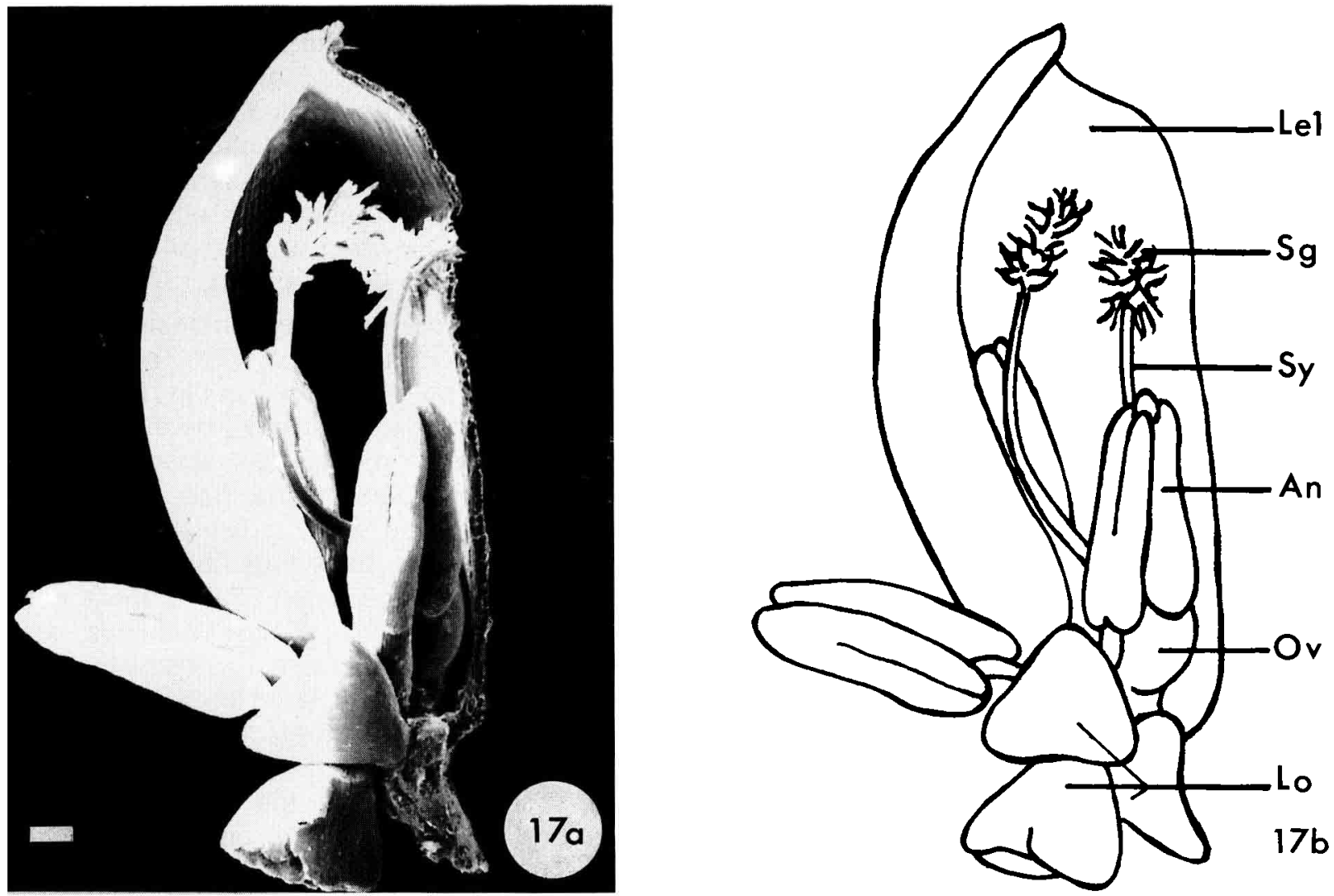

Fig 17. A fertile floret partly dissected to reveal the fertile floral parts (82-day-old plant, Cv "Change"). Stigma (Sg), style (Sy), anther (An), ovule (Ov), lodicule (Lo), lemma (Le1). a. SEM photomicrograph. Scale bar $=100 \mu \mathrm{m}$. b. Drawing of the same apex.
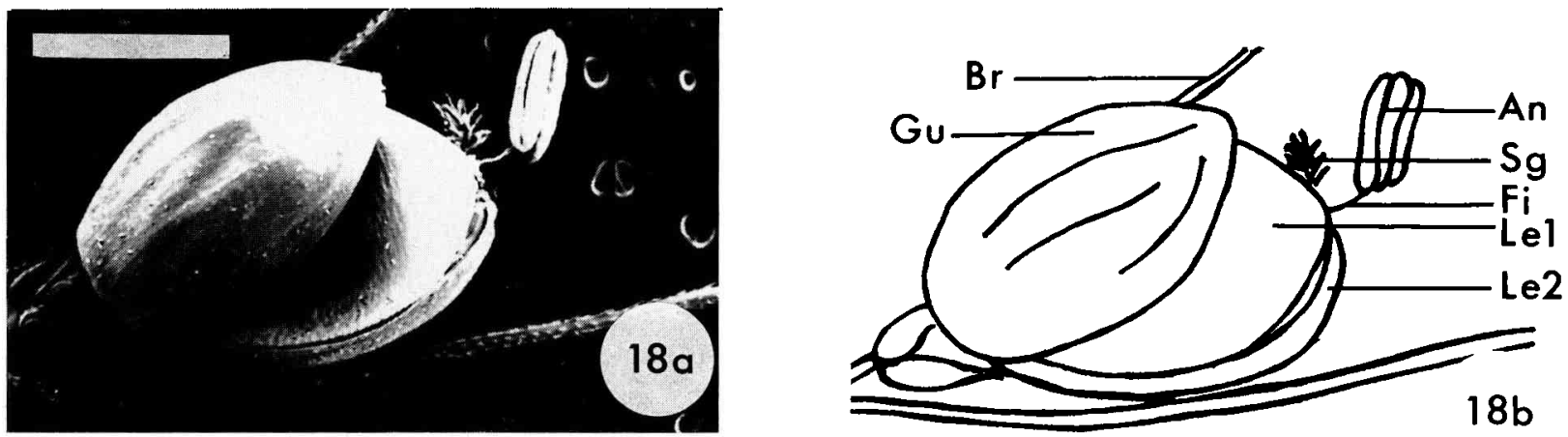

Fig 18. A spikelet at anthesis (87-day-old plant, $\mathrm{CV}_{\mathrm{V}}$ "Change"). Labelling as in figure 17; filament (Fi), lemma of floret 2 (Le2). a. SEM photomicrograph. Scale bar $=1000 \mu \mathrm{m}$. b. Drawing of the same apex.

For foxtail millet crop, a stress occurring between the stage $B$ and antheșis ie for the 2 varieties between 705 and 1000 degreedays, might disturb spikelet formation and panicle size (grain number). The panicle size is determined during the period of spikelet formation (product of rate and duration) but stress conditions during floret development can lead to extensive spikelet mortality and subsequent decrease in grain number. 1000 grain weight is determined by the quantity of assimilates available for transport to the panicle between anthesis and maturity. Stress during this period, ie from 1000 to 1700 degree-days for the 2 varieties, can lead to grain filling perturbation, therefore associated with a decrease in 1000-grain weight.

The effect of stress conditions (competition for light) upon yield is currently being investigated in both varieties. These results will be presented in a subsequent paper. 


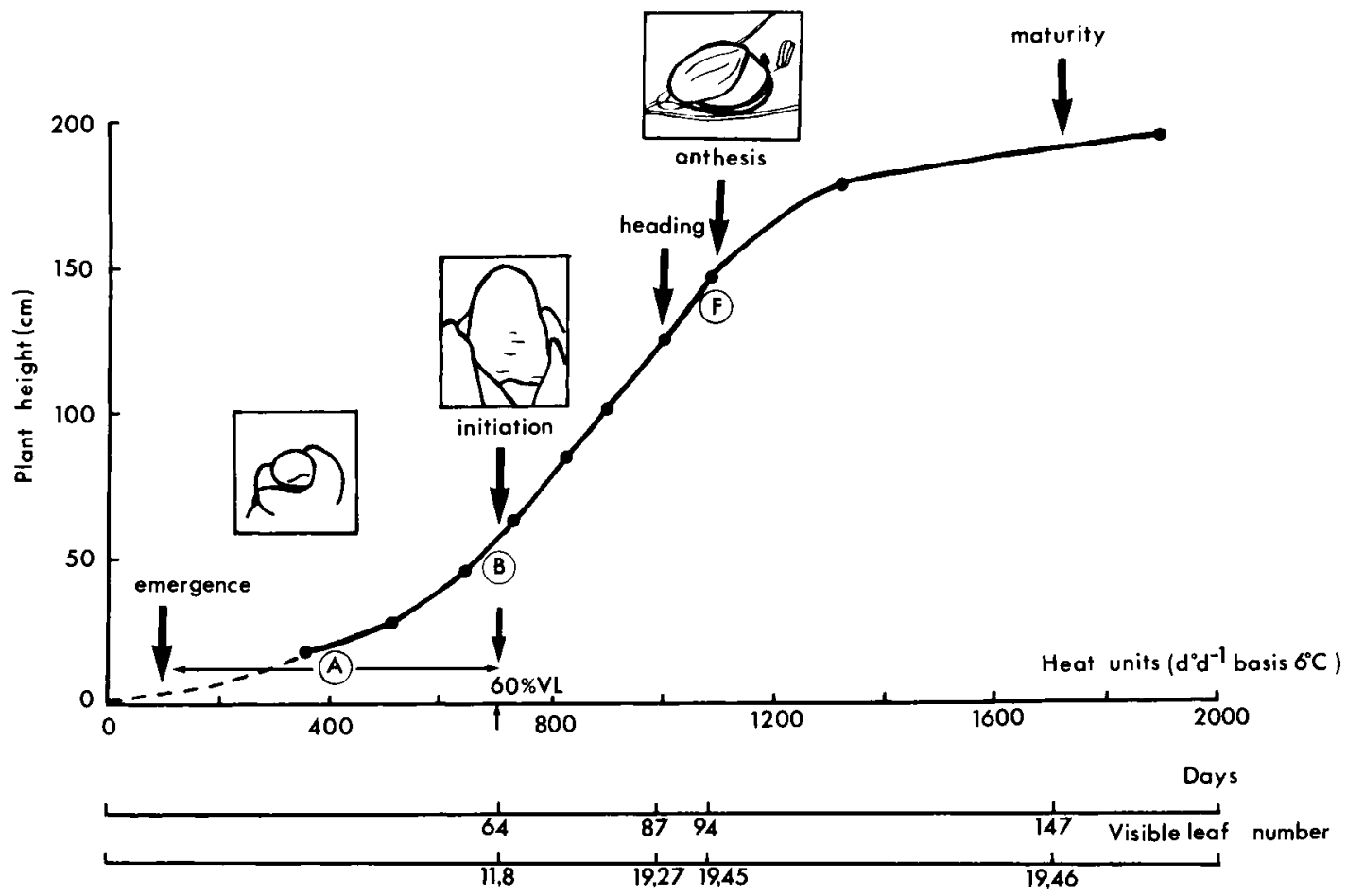

Fig 19. Correspondence between reference stages of development and growth in Millet. CV "Burganjou". \% VL: visible leaves / total leaf number (\%); A: vegetative phase; B: transition stage (panicle initiation); $F$ : anthesis stage.

\section{CONCLUSION}

Because of the influence of management and environment upon yield components, it is important to record the main developmental stages of foxtail millet (stage $B$, inflorescence differentiation stages, heading and anthesis).

The mature panicle of foxtail millet consists of secondary and tertiary clusters. Throughout floral ontogenesis, the branching is more prolific at the base of the inflorescence during the stage $\mathrm{C} 2$ (differentiation of the 3rd order branches) and the 4th order protuberances arise in a greater number in this part of the panicle (stage C3). As a result, the number of spikelets within the tertiary clusters and the number of tertiary clusters are more important. Thus, the 2nd and 3rd order branches are longer at the bottom of the panicle. The top of the panicle is more compact and the secondary clusters are not so clearly individualized as those found at the bottom.

During the spikelet and floret formation we have recorded different developmental stages, for the same cluster, and it is not possible to describe the maturation sequence of the individual florets within the 2nd and 3rd order clusters. As a general rule, the first stages of floral ontogenesis and spikelet maturation occur in the upper part of the panicle and proceed downwards and upwards. As the developmental stages and the size of spikelets are heterogenous within the panicle, it is difficult to record developmental stages such as anthesis.

\section{ACKNOWLEDGMENTS}

Thanks are due to $\mathrm{J}$ Mercier for technical assistance. This research was financially supported by the Garno Aeda Foundation.

\section{REFERENCES}

Anderson S (1952) Methods for determining stages of development in barley and oats. Physiol Plant 5, 199-210

Bloc D, Gouet JP (1977) Influence des sommes de températures sur la floraison et la maturité du maïs. Ann Amelior Plant 28, 89-111

Bonnett OT (1935) The development of the barley spike. J Agric Res 51, 451-457 
Bonnett OT (1936) The development of the wheat spike. J Agric Res 53, 445-451

Bonnett OT (1937) The development of the oat panicle. J Agric Res 54, 927-931

Bonnett OT (1948) Ear and tassel development in maize. Ann Mo Bot Gard 35, 269-287

Bonnett OT (1966) Inflorescences of maize, wheat, rye, barley and oats: their initiation and development. University of Illinois College of Agriculture. Agric Exp Stat Bull 721, 105

Brabant $P$, Belliard J, Metailie G, Nguyen Van E, Poirier S, Poirier B, Pernes J (1981) Données préliminaires pour la réintroduction et la culture du millet Setaria en France. J Agric Tradit Bot Appl XXVIII, 3-4, 309-328

Gay JP, Menetrier MA (1978) Morphogénèse des Organes Reproducteurs chez le Mä̈s: Échelle de Notation des Stades. Publ AGPM, Paris, $38 \mathrm{pp}$

Kirby EJM (1974) Ear development in spring wheat. J Agric Sci (Camb) 82, 437-447

Kirby EJM, Appleyard M (1984) Cereal Development Guide. NAC Unit, $96 \mathrm{pp}$
Large EC (1954) Growth stages in cereals, illustration of the Feekes scale. Plant Pathol 3, 128129

Sharman BC (1947) The biology and developmental morphology of the shoot apex in the Gramineae. New Phytol 46, 20-34

Sundberg MD (1987) Development of the mixed inflorescence in Zea diploperennis IItis, Doebley and Guzman (Poaceae). Bot J Linn Soc 95, 207-216

Sundberg MD, Orr AR (1986) Early inflorescence and floral development in Zea diploperennis, diploperennial teosinte. Am J Bot 73, 1699-1712

Sundberg MD, Orr AR (1990) Inflorescence development in two annual teosintes: Zea mays subsp mexicana and Zea mays subsp parviglumis. Am J Bot 77, 141-152

Torigoe Y, Kurihara H (1981) Developmental morphology and yield determining process of maize. Jpn Agic Res $Q$ 15, 85-91

Zadocks JC, Chang TT, Konzach CF (1974) A decimal code for the growth stages of cereals. Weed Res 14, 415-421 